\title{
Concepts in Understanding Oral Field Cancerization: A Brief Review
}

\author{
Snehanjan Sarangi', Ritesh Aich ${ }^{2}$ \\ ${ }^{1}$ Department of Dentistry, Dental Surgeon, Chanditala Rural Hospital, Hooghly, Kolkata, West Bengal, India, ${ }^{2}$ Department of Oral \\ Medicine and Radiology, Dr. R. Ahmed Dental College and Hospital, Kolkata, West Bengal, India
}

Email for correspondence: babi.sarangi@gmail.com

\begin{abstract}
The concept "field effect in cancer" originated in 1953, from the histopathological observations of Slaughter and colleagues regarding the occurrence of multiple primary oral squamous cell carcinomas and their local recurrences. There are two fundamental theories regarding the development of oral field cancerization (OFC) which includes the "classical" and the "clonal" mechanism. The classical view hypothesizes that the entire epithelial surface of the upper aerodigestive tract has an increased risk for the development of premalignant disorders because of multiple genetic abnormalities in the whole tissue region; owing to prolonged exposures of susceptible carcinogens as a result of tobacco or alcohol consumption. While the clonal theory believes that there always exists a field with genetically altered cells having a high risk of developing premalignant and malignant disorders. Here, the developing separate tumors from a genetically individually altered stem cell in the extended field, share the same clonal origin, and some degree of genetic similarity. Modern molecular and histological technologies exploring the tissue abnormalities in OFC have been performed. Herein, we have briefly discussed regarding the concepts of field cancerization along with the various diagnostic molecular techniques and the therapeutic aspects.
\end{abstract}

Key words: Field effect, molecular techniques, premalignant and malignant disorders, therapeutic aspects

\section{INTRODUCTION}

The concept of field cancerization was introduced by Slaughter et al., in $1953 .{ }^{[1]}$ In this classic paper, the authors studied oral squamous cell carcinomas in 783 patients from the gross and microscopic standpoint. They found 88 instances of independent multiple tumors. They also observed microscopic abnormalities (hyperplastic or atypical epithelium) in grossly benign contiguous tissue. Based on these findings, they suggested field cancerization to be an important factor in recurrence of oral cancer after therapy. The deduction drawn was that the regional mucosa had undergone a marked change, probably owing to prolonged carcinogen exposure (from tobacco,

\section{Quick Response Code Article Info:}

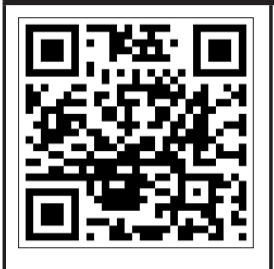

doi: 10.5866/2017.9.10164

Received: $30-08-2017$

Revised: 25-09-2017

Accepted: $30-09-2017$

Available Online: 27-11-2017 (www.nacd.

in)@ NAD, 2017 - All rights reserved alcohol, etc.) and was, therefore, more susceptible to the development of multiple foci of malignant transformation; however, this phenomenon is not related to metastasis of tumor cells. ${ }^{[2,3]}$ Identification of distinct biological markers to depict the field change in malignant transformations is a significant milestone in this regard. ${ }^{[4]}$ Many researchers have employed recent molecular techniques to elucidate the mechanism that underlies the clinical phenomenon of field cancerization. Chemoprevention can be performed to halt, delay, or reverse malignant progression in tissues at risk to develop invasive cancer $^{[5-7]}$ We have tried to brief the current concepts regarding field cancerization, clarified the related terminologies such as second primary tumors (SPT), synchronous/metachronous primaries, and distant primaries; along with an enumeration of a few relevant molecular modalities and therapeutic implications to elucidate the understanding of oral field cancerization (OFC).

\section{HISTORY OF FIELD CANCERIZATION}

The concept of field cancerization was first introduced by Slaughter et al., in 1953, when he 
analyzed the tissues adjacent to fields of squamous cell carcinoma. ${ }^{[8]}$ The concept was first examined in the upper aerodigestive tract, where multiple primary tumors and local recurrent tumors originated from the anaplastic tendency of multiple cells. The term lateral cancerization was used to denote the lateral spread of tumors, which occurs due to a progressive transformation of the tissue adjacent to the tumor rather than the expansion of preexisting cancer cells into the adjacent tissue. ${ }^{[9]}$ Later, the expression of field cancerization was adopted, as these findings suggested that prolonged exposure to carcinogen-induced mucosal changes makes the adjacent area susceptible to the development of multiple malignant foci. The oral cavity was proven to be most susceptible to this field cancerization process, as it is exposed to a varied range of environmental and chemical carcinogenic insults, which affect the entire mucosa and lead to the simultaneous occurrence of premalignant sites.

\section{VARIOUS THEORIES REGARDING CONCEPT OF OFC}

The concept of field cancerization can be explained in various ways.

In the "classical view", which is used in common parlance, large areas of the aerodigestive tissue are affected by extended exposure to carcinogens, from various noxious stimuli. In this preconditioned epithelium, multifocal carcinomas can develop as a result of independent mutations, and thus would not be genetically related to each other [Figure 1a].

The "clonal theory" of the field concept may explain the phenomenon of SPTs. As per this concept, a single cell is transformed and gives rise to one large, extended, premalignant field by clonal expansion, and gradual replacement of normal mucosa by atypical ones. In this field of various subclones, two separate tumors can develop after the accumulation of additional genetic alterations. Both tumors have the same clonal origin and would thus share at least some degree of genetic similarity, which occurred before the initial clonal expansion.

This theory was further elaborated by Monique GCT van Oijen et al., in 2000, explained on the basis of two types of migration of already genetically transformed cells. ${ }^{[10]}$

a. Migration of tumor cells by saliva (micrometastasis) [Figure 1b]. b. Intraepithelial migration of the progeny of the initially transformed cells [Figure 1c).

Clonal divergence within the contiguous field will ultimately lead to the emergence of a primary tumor, which will share many genetic alterations with the surrounding cells of the precancerous field. Such clonally related fields can be much larger than the actual carcinoma. ${ }^{[1]}$

\section{CRITERIA USED TO DIAGNOSE MULTIPLE FIELD CARCINOMAS}

Warren and Gates initially formulated a set of criteria to diagnose multiple primary carcinomas which were modified later by Hong et al. ${ }^{[12,13]}$ The criteria to be met are as follows: (i) The neoplasm must be distinct and anatomically separate. A multicentric primary neoplasm is diagnosed when a dysplastic mucosa is present next to it; (ii) a potential second primary carcinoma which represents a metastasis or a local relapse should be excluded. It has to occur 3 years after the initial diagnosis, or it should be separate from the first tumor by at least $2 \mathrm{~cm}$ from the normal epithelium.

Numerous factors determine the progression of a field or patch of vulnerable dysplastic mucosae into a new tumor and must, therefore, be accurately reviewed and followed up. A premalignant field often requires a much longer period of approximately 67-96 months to progress into an invasive carcinoma. ${ }^{[14,15]}$

\section{SPT, SYNCHRONOUS AND METACHRONOUS PRIMARIES, AND SECOND FIELD TUMORS (SFT)}

Long-term survival of head and neck cancer patients has not significantly improved in the last 20 years, despite advances in research, diagnosis, and therapy. An important reason for this lack of progress is the development of SPT in the upper aerodigestive tract. ${ }^{[16,17]}$ SPTs which occur simultaneously or within 6 months of index (primary) tumor are termed as synchronous primaries, and those SPTs, which occur after 6 months of index tumor are named as metachronous primaries. ${ }^{[18]}$ The incidence of second primary synchronous or metachronous tumor is increasing and reported as high as $10 \%$.

The term "SFT" is employed for those lesions that are anatomically distinct but demonstrate genetic similarities. For those tumors that arise in the same anatomic location postresection, SFTs can be identified as well. ${ }^{[19]}$ Hence, true second primaries 


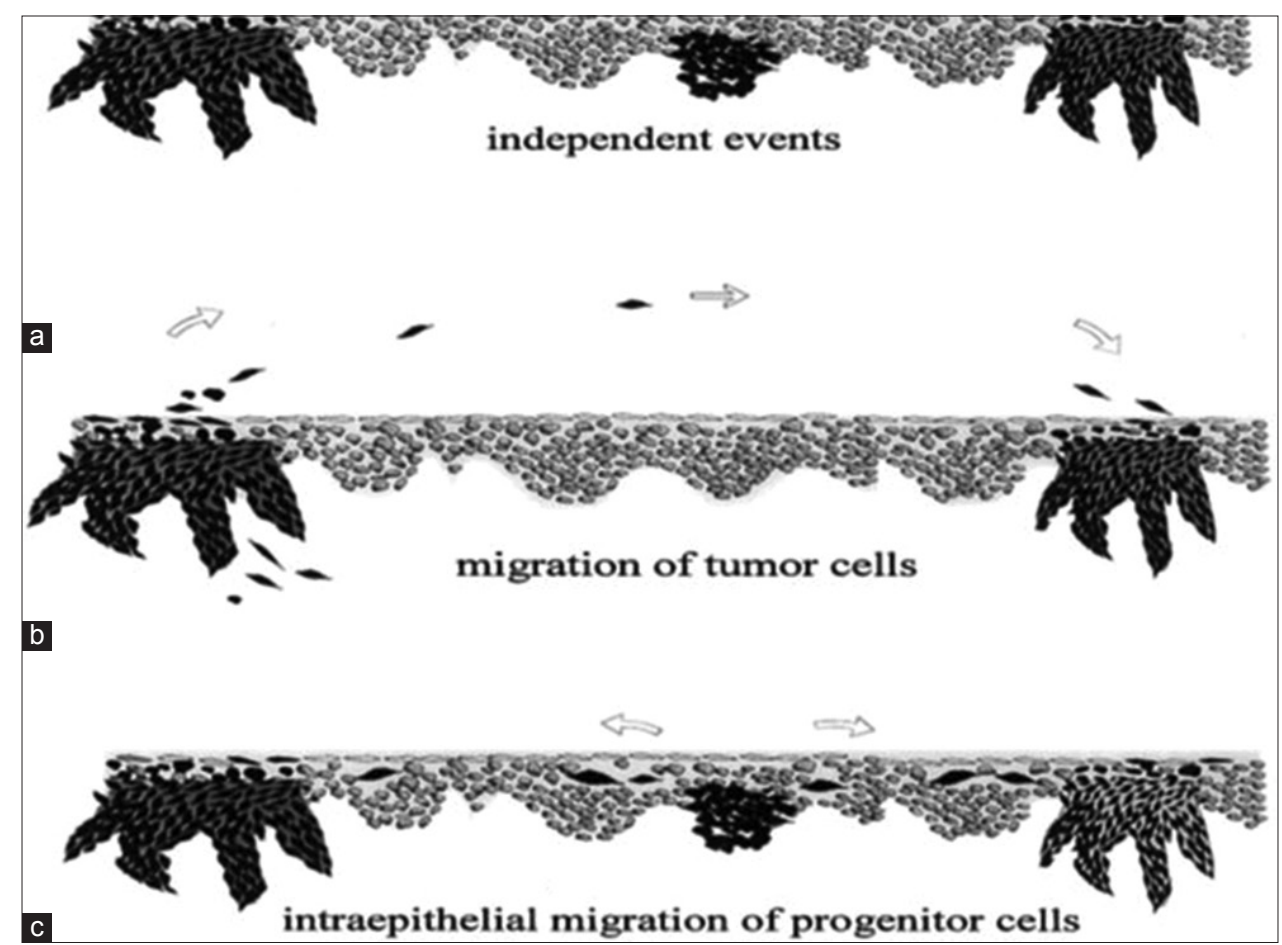

Figure 1: Various mechanisms of oral field cancerization: (a) Multifocal tumors developing independently as a result of wide exposure of oral mucosa to carcinogens (Slaughter's concept); (b) micrometastasis of tumor cells (e.g., through saliva); and (c) intraepithelial migration of the progeny of the initially transformed cells

are lesions which share no genetic similarities and arise as a result of independent events.

\section{DISTANT SECOND LESION}

A common conduit of mucosa transitions through the oral cavity, lungs, and esophagus, lending itself to functional adaptations of these anatomically variable zones; therefore, a constant exposure pathway to the mucosa from environmental carcinogens is evident. As such, Slaughter's observation of frequent synchronous or metachronous tumors in the aerodigestive tract is expected, based on elevated risk from carcinogen exposure alone. However, in the cases of synchronous tumors separated by large distances, it is of interest if these tumors arose as a result of independent events or from the same progenitor clone that subsequently migrated.

Patients with head and neck squamous cell carcinomas (HNSCC) and concurrent esophageal squamous cell lesions have been studied for the relationship between the two tumors. One study looking at 16 such patients demonstrated, by the use of microsatellite markers, that the lesions were not clonally related in 14 of the patients. ${ }^{[20]}$ Therefore, it is generally assumed that esophageal lesions in conjunction with HNSCCs represent two separate primary tumors rather than metastases.

A different study examined the question of synchronous lung tumors and their relationship to HNSCC. ${ }^{[21]}$ Samples from 16 patients with HNSCC and a concurrent solitary lung lesion were tested by microsatellite analysis. 10 of 16 samples (63\%) demonstrated concordant patterns of loss at all loci tested, suggesting that the majority of solitary lung lesions were in fact metastases rather than separate primary tumors.

Therefore, the distance between two malignancies does not necessarily predict clonality. As a general rule, distant, peripheral, solitary, and squamous lung lesions in conjunction with HNSCC are thought to be metastases, and concurrent esophageal tumors are thought to be separate primary tumors.

\section{FIELD CANCERIZATION MODEL}

The process of carcinogenesis begins with a stem cell which develops one or more genetic and epigenetic alterations. Subsequently, a clone of genetically altered cells forms a patch or a cluster. 
As a result of further genetic alterations, the stem cell escapes the normal growth control pattern and gains advantage by developing into an expanding clone. Later, the lesions progress and become a field which displaces laterally the normal epithelium. The field, having a genetically altered clonal unit, has an enhanced proliferative activity which is the driving force of the entire process. ${ }^{[22]}$ The carcinogenesis model is based on a monoclonal origin and includes three main steps: ${ }^{[23]}$

- First phase (patch formation): Conversion of a single stem cell (patch) into a group of cells (clone) which carry the genetic alterations without a proper growth control pattern.

- Second phase (clonal expansion): Additional genetic alterations develop and the patch proliferates taking advantage of its enhanced growth potential and forms a field which displaces the normal epithelium.

- Third phase (transition to tumor): The clone or field eventually turns into an overt carcinoma with invasive growth and metastasis.

\section{MOLECULAR CONCEPTS OF FIELD CANCERIZATION}

The expression of various markers in the epithelium and connective tissue components can help determine the field cancerization. Molecular findings indicate the presence of cytokeratin 7,8 , 13,16 , and 19 at abnormal sites and abnormal levels within the epithelium. ${ }^{[24,25]}$ Furthermore, well-defined foci of cyclin D1 expression are present in the normal mucosa adjacent to the carcinomatous tissue. Several studies have shown increased numbers of epidermal growth factor receptors in tumor-associated normal mucosae. ${ }^{[26,27]}$ Upregulated Ki-67 and transforming growth factor (TGF) levels were also evident. ${ }^{[28,29}$

Furthermore, marked variations in the expression of enzymes were detected in the epithelium. The expression of isoenzyme glutathione S-transferase was found to be significantly higher in the suprabasal and superficial layers of the normal oral mucosa in head and neck carcinoma patients. ${ }^{[30]}$ The most promising marker of field cancerization is p53 which shows a strong positive correlation with the progression of the tumor from a benign to a malignant state. ${ }^{[31]}$

\section{MOLECULAR METHODS FOR DETERMINATION OF CLONALITY}

A single cell, altered by inactivation of a tumor suppressor gene(s) and/or activation of an oncogene(s), will gain a growth advantage and expand to form a clonal mass of cells or tumor. ${ }^{[32]}$ This can be visualized as a dynamic process. The underlying technique utilizes few significant criteria, namely, identification of early, shared genetic alterations that are unique to the lesions and not found elsewhere in normal mucosa. Thus, these molecular patterns form a type of a DNA fingerprint. The determination of clonality, initially, was partly successful by techniques such as karyotype analysis, detection of p53 mutations, and X-chromosome inactivation. Finally, "microsatellite alterations" have been concluded as overall effective method for demonstrating clonality. Smokinginduced morphogenetic changes have been depicted in Figure 2. ${ }^{[33]}$

\section{DETECTION OF SECOND PRIMARIES AND METASTATIC DEPOSITS}

Specialized radiographic techniques such as computed tomography, magnetic resonance imaging, and especially fluorodeoxyglucose-positron emission tomography play a pivotal role in diagnosing SPT and concurrent metastatic deposits in the body. ${ }^{[34]}$ Vital staining with toluidine blue and fluorescence visualization of SPTs have also been carried out. Blue excitation light (400-460 nm) can discern the presence of subclinical oral neoplasia. ${ }^{[35]}$

\section{DIFFERENTIATION OF RECURRENT/ METASTATIC AND SPTS}

A study conducted by Gasparotto et al., in 1995, concluded that p53 mutations help us to differentiate between recurrent and SPT. ${ }^{[36]}$ p53 mutations are a very early and polymorphic phenomenon, in which a recurrence/metastasis must retain the same mutation as the primary tumor, whereas independent tumors are likely to display a different p53 gene status.

\section{THERAPEUTIC ASPECTS IN FIELD CANCER}

The presence of altered atypical neoplastic fields of mucosa remaining beyond the reaches of resection has been shown both histologically and on a molecular basis. Initial studies performed demonstrated that p53 mutations noted in histologically normal margins could be detected, and in fact, there was a higher incidence of local recurrence in those patients with known mutations in the altered margins. ${ }^{[37]}$ The histologically benign mucosa often can progress to further premalignant or malignant disease. ${ }^{[38]}$ 


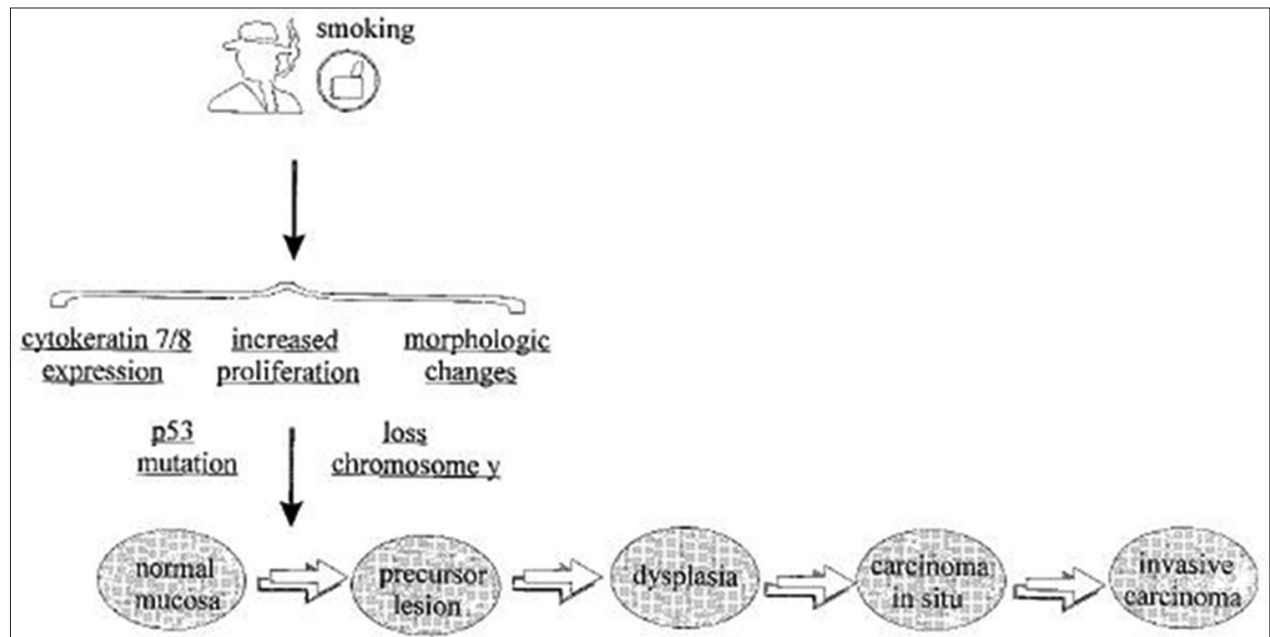

Figure 2: Carcinogenic agents in smoking leading to field changes encompassing a very broad spectrum from normal mucosa to invasive carcinoma owing to accumulation of molecular and genetic changes

The presence of altered clones at mucosal margins may point toward aggressive therapy including chemopreventive or radiotherapy to treat altered clonal patches that are unable to be detected grossly and are beyond the initial scope of surgical excision. Current management is often site-specific: Recurrent oral premalignant disease is often treated by surgical excision, whereas diffuse high-grade premalignant changes in the laryngeal mucosa are frequently treated with radiotherapy. However, further, future studies will only broaden the horizon in these aspects and will help to determine the potential genetic targets associated with therapeutic applications.

Chemoprevention could be used to prevent the recurrence of cancer after surgery. Several agents are there, but perhaps, the most widely studied compound in the upper aerodigestive tract has been 13-cis-retinoic acid. This family of chemicals has been shown to play a role in the differentiation, development, and growth of epithelial cells. ${ }^{[39]}$ Other compounds, such as cyclooxygenase-2 (COX-2) inhibitors, are being studied as chemopreventive agents owing to increased COX-2 levels in HNSCC. ${ }^{[40]}$

\section{SUMMARY AND CONCLUSION}

The field effect in carcinogenesis, in which a morphologically normal epithelium develops into a tumor, is the result of expansion of a genetically abnormal clone. The term, "field effect," remains controversial even after half a century. Here, precancerous cells that are in proximity to tumors have some of the genetic fingerprints that are present in the fully developed tumors. The field cancerization theory also emphasizes the high probability of recurrences in patients with head and neck squamous cell carcinoma. Therefore, a frequent oral examination with histological studies and molecular testing is mandatory for patients after surgery, especially for those at high risk of developing malignancies. Although numerous markers have been identified to help determine the field effect, the entire process is still shroud in mystery. Further molecular genetic analyses will serve to broaden the scope of research regarding $\mathrm{OFC}$ in the ensuing days.

\section{REFERENCES}

1. Slaughter DP, Southwick HW, Smejkal W. Field cancerization in oral stratified squamous epithelium; clinical implications of multicentric origin. Cancer 1953;6:963-8.

2. Slaughter DP. Multicentric origin of intraoral carcinoma. Surgery 1946;20:133-46.

3. van Oijen MG, Slootweg PJ. Oral field cancerization: Carcinogen-induced independent events or micrometastatic deposits? Cancer Epidemiol Biomarkers Prev 2000;9:249-56

4. Kale AD, Mane DR, Babji D, Gupta K. Establishment of field change by expression of cytokeratins 8/18, 19, and MMP-9 in an apparently normal oral mucosa adjacent to squamous cell carcinoma: A immunohistochemical study. J Oral Maxillofac Pathol 2012;16:10-5.

5. Tanaka T. Chemoprevention of oral carcinogenesis. Eur J Cancer B Oral Oncol 1995;31B:3-15.

6. Tanaka T. Effect of diet on human carcinogenesis. Crit Rev Oncol Hematol 1997;25:73-95.

7. Tanaka T. Chemoprevention of human cancer: Biology and 
therapy. Crit Rev Oncol Hematol 1997;25:139-74.

8. Slaughter M, Danely P, Harry W. Field cancerization in oral stratified squamous epithelium clinical implications of multicentric origin. Cancer 1953;6:950-8.

9. Kaufmann R. The concept of field cancerization. Melanoma Res 2010;20:e13-4.

10. van Oijen MG, Vd Straat FG, Tilanus MG, Slootweg PJ. The origins of multiple squamous cell carcinomas in the aerodigestive tract. Cancer 2000;88:884-93.

11. Rhiner C, Moreno E. Super competition as a possible mechanism to pioneer precancerous fields. Carcinogenesis 2009;30:723-8.

12. Hong WK, Lippman SM, Itri LM, Karp DD, Lee JS, Byers RM, et al. Prevention of second primary tumors with isotretinoin in squamous-cell carcinoma of the head and neck. N Engl J Med 1990;323:795-801.

13. Warren S, Gates O. Multiple primary malignant tumors. A survey of the literature and a statistical study. Am J Cancer 1932;16:1358-414.

14. Scholes AG, Woolgar JA, Boyle MA, Brown JS, Vaughan ED, Hart CA, et al. Synchronous oral carcinomas: Independent or common clonal origin? Cancer Res 1998;58:2003-6.

15. Mao L, Lee JS, Fan YH, Ro JY, Batsakis JG, Lippman S, et al. Frequent microsatellite alterations at chromosomes 9p21 and 3p14 in oral premalignant lesions and their value in cancer risk assessment. Nat Med 1996;2:682-5.

16. Lippman SM, Hong WK. Second malignant tumors in head and neck squamous cell carcinoma: The overshadowing threat for patients with early-stage disease. Int J Radiat Oncol Biol Phys 1989;17:691-4.

17. Cooper JS, Pajak TF, Rubin P, Tupchong L, Brady LW, Leibel SA, et al. Second malignancies in patients who have head and neck cancer: Incidence, effect on survival and implications based on the RTOG Gluckman experience. Int J Radiat Oncol Biol Phys 1989;17:449-56.

18. de Vries N. The magnitude of the problem. In: De Vries N, Jack L, editors. Multiple Primary Tumors in the Head and Neck. Stuttgart, Germany: Georg Thieme Verlag; 1990. p. 1-29.

19. Braakhuis BJ, Tabor MP, Leemans CR, van der Waal I, Snow GB, Brakenhoff RH. Second primary tumors and field cancerization in oral and oropharyngeal cancer: Molecular techniques provide new insights and definitions. Head Neck 2002;24:198-206

20. Califano J, Leong PL, Koch WM, Eisenberger CF, Sidransky D, Westra WH. Second esophageal tumors in patients with head and neck squamous cell carcinoma: An assessment of clonal relationships. Clin Cancer Res $1999 ; 5: 1862-7$

21. Leong PP, Rezai B, Koch WM, Reed A, Eisele D, Lee DJ, et al. Distinguishing second primary tumors from lung metastases in patients with head and neck squamous cell carcinoma. J Natl Cancer Inst 1998;90:972-7.

22. Tabor MP, Brakenhoff RH, van Houten VM, Kummer JA, Snel MH, Snijders PJ, et al. Persistence of genetically altered fields in head and neck cancer patients: Biological and clinical implications. Clin Cancer Res 2001;7:1523-32.

23. Izzo JG, Papadimitrakopoulou VA, Li XQ, Ibarguen H, Lee JS, Ro JY, et al. Dysregulated cyclin D1 expression early in head and neck tumorigenesis: In vivo evidence for an association with subsequent gene amplification. Oncogene 1998 5;17:2313-22.

24. Partridge M, Pateromichelakis S, Phillips E, Emilion G, Langdon J. Profiling clonality and progression in multiple premalignant and malignant oral lesions identifies a subgroup of cases with a distinct presentation of squamous cell carcinoma. Clin Cancer Res 2001;7:1860-6.

25. Shin DM, Voravud N, Ro JY, Lee JS, Hong WK, Hittelman WN. Sequential increases in proliferating cell nuclear antigen expression in head and neck tumorigenesis: A potential biomarker. J Natl Cancer Inst 1993;85:971-8

26. Werkmeister R, Brandt B, Joos U. The erbB oncogenes as prognostic markers in oral squamous cell carcinomas. Am J Surg 1996;172:681-3.

27. Szymanska K, Levi JE, Menezes A, Wünsch-Filho V, Eluf-Neto J, Koifman S, et al. TP53 and EGFR mutations in combination with lifestyle risk factors in tumours of the upper aerodigestive tract from South America. Carcinogenesis 2010;31:1054-9.

28. Bosch FX, Ouhayoun JP, Bader BL, Collin C, Grund C, Lee I, et al. Extensive changes in cytokeratin expression patterns in pathologically affected human gingiva. Virchows Arch B Cell Pathol Incl Mol Pathol 1989;58:59-77.

29. Schwint AE, Savino TM, Lanfranchi HE, Marschoff E, Cabrini RL, Itoiz ME. Nucleolar organizer regions in lining epithelium adjacent to squamous cell carcinoma of human oral mucosa. Cancer 1994;73:2674-9.

30. Bongers V, Snow GB, de Vries N, Cattan AR, Hall AG, van der Waal I, et al. Second primary head and neck squamous cell carcinoma predicted by the glutathione S-transferase expression in healthy tissue in the direct vicinity of the first tumor. Lab Invest 1995;73:503-10.

31. el-Naggar AK, Lai S, Luna MA, Zhou XD, Weber RS, Goepfert $\mathrm{H}$, et al. Sequential p53 mutation analysis of preinvasive and invasive head and neck squamous carcinoma. Int J Cancer 1995;64:196-201.

32. Fearon ER, Vogelstein B. A genetic model for colorectal tumorigenesis. Cell 1990;61:759-67.

33. Van Oijen MG, Poorts LK, Slootweg PJ. Mucosal changes in head and neck cancer. Incipient tumors or micrometastases? J Cancer Res Clin Oncol 1999;125:105.

34. Wax MK, Myers LL, Gabalski EC, Husain S, Gona JM, Nabi H. Positron emission tomography in the evaluation of synchronous lung lesions in patients with untreated head and neck cancer. Arch Otolaryngol Head Neck Surg 2002;128:703-7.

35. Westra WH, Sidransky D. Fluorescence visualization in oral neoplasia. shedding light on an old problem. Clin Cancer Res 2006;12:6594-97.

36. Gasparotto D, Maestro R, Barzan L, Vukosavljevic T, Doglioni C, Sulfaro S, et al. Recurrences and second primary tumours in the head and neck region: Differentiation by p53 
mutation analysis. Ann Oncol 1995;6:933-9.

37. Brennan JA, Mao L, Hruban RH, Boyle JO, Eby YJ, Koch WM, et al. Molecular assessment of histopathological staging in squamous-cell carcinoma of the head and neck. N Engl J Med 1995;332:429-35.

38. Califano J, Westra WH, Koch W, Meininger G, Reed A, Yip L, et al. Unknown primary head and neck squamous cell carcinoma: Molecular identification of the site of origin.
J Natl Cancer Inst 1999;91:599-604.

39. Armstrong WB, Meyskens FL Jr. Chemoprevention of head and neck cancer. Otolaryngol Head Neck Surg 2000;122:728-35.

40. Chan G, Boyle JO, Yang EK, Zhang F, Sacks PG, Shah JP, et al. Cyclooxygenase-2 expression is up-regulated in squamous cell carcinoma of the head and neck. Cancer Res 1999;59:991-4. 